\title{
Habitat use governs distribution patterns of saprophagous (litter-transforming) macroarthropods - a case study of British woodlice (Isopoda: Oniscidea)
}

\author{
Bethan V. PURSE ${ }^{1}$, Steve J. GREGORY ${ }^{2}$, Paul HARDING ${ }^{3}$ and Helen E. ROY ${ }^{3}$ \\ ${ }^{1}$ Centre for Ecology \& Hydrology, Bush Estate, Penicuik, Midlothian, EH26 0QB, UK; e-mail: beth@ceh.ac.uk \\ ${ }^{2}$ British Myriapod \& Isopod Group, www.BMIG.org.uk; e-mail: steve.gregory@earthtrust.org \\ ${ }^{3}$ Biological Records Centre, Centre for Ecology \& Hydrology, Benson Lane, Crowmarsh Gifford, Wallingford, OX10 8BB, UK; \\ e-mails: pha@ceh.ac.uk; hele@ceh.ac.uk
}

\begin{abstract}
Key words. Crustacea, Isopoda, Oniscidea, decomposition, habitat breadth, niche breadth, range size, recording intensity, saprophagous
\end{abstract}

\begin{abstract}
Despite the importance of saprophagous macroarthropods as key facilitators of plant litter decomposition within ecosystems and their likely sensitivity to global climate change and land-use change, a lack of ecological data has precluded attempts to explain their distribution patterns in terms of traits. Using an extensive set of large-scale and long-term biological records, the distribution patterns of 33 woodlice (Crustacea: Oniscidea) species in Britain were characterised by their range size (area of occupancy) and aggregation (degree to which occupied squares are clustered across the range). Body size and seven ecological traits were examined as correlates of range size and fill, while controlling for phylogeny and recording intensity, and comparing fine and broad-scale measures of habitat heterogeneity. Species that used a greater diversity of habitats had larger range sizes. Broad categorisation of habitats (by dominant vegetation) alongside other traits was less accurate in predicting range size than fine-scale habitat (microsites where individuals were discovered) data. The latter explained $25 \%$ more variance than broad-scale habitat data, highlighting the value of coupling biological recording of species with data on micro-habitat. Habitat use is an important trait in explaining distribution patterns and we conclude that ensuring land cover heterogeneity will favour conservation of saprophagous macro-arthropod diversity.
\end{abstract}

\section{INTRODUCTION}

Range size is a key variable in macro-ecological theory (Holt, 2003) with multiple links to other fundamental ecological and evolutionary characteristics of a species such as metapopulation size and abundance (Gaston et al., 1997; Cowley et al., 2001), geographic location (Rapoport's rule' Gaston et al., 1998), speciation and extinction risk (Jones et al., 2003). Range size is often defined as the area of occupancy (AOO), namely the area within a species' distributional limits where it actually occurs (Gaston \& Fuller, 2009). Distributions patterns can further be characterised in terms of the degree to which occupied grid squares are clustered with other occupied squares across the range at a particular scale of observation (Wilson et al., 2004), sometimes known as aggregation. Range size and aggregation have been found to be strong predictors of range expansion and contraction across some taxa even at a national scale i.e. within a subset of the global range (Wilson et al., 2004; Fattorini, 2011).

Identifying traits that correlate with range size (and aggregation) is the first step in discovering the causal explanation for realised ranges (Beck \& Kitching, 2007) and leads to predictions that may assist with developing conservation priorities and contribute to our general understanding of correlates of rarity and decline (Fitzpatrick et al., 2007). Ecological correlates of range size have been examined for a range of arthropod groups including Carabid beetles (Gutierrez \& Menendez, 1997),
Sphingid moths (Beck \& Kitching, 2007), spiders (Bonte et al., 2004) and butterflies (Cowley et al., 2001) but not for saprophages that play a key role in ecosystem functioning.

Niche size, whether encompassing climatic tolerance, habitat or diet breadth, is expected to influence range size and has been proposed as a mechanism underpinning relationships between range size and local abundance (Gaston et al., 1997). Critical niche dimensions are likely to vary between trophic or functional groups. For herbivorous and predatory arthropods that have relatively narrow diet ranges overall, range characteristics have been correlated with both diet breadth (Brandle et al., 2002; Beck \& Kitching, 2007) as well as habitat breadth (Brandle et al., 2002). Saprophagous or litter-transforming (Lavelle et al., 1997) macro-arthropods by contrast tend to show lower levels of host or dietary specialisation than other functional groups (Maraun et al., 2003), with patterns in richness of litter-dwelling arthropods for example being largely uncorrelated with patterns of tree diversity (Donoso et al., 2010). Climatic tolerance (Warburg et al., 1984), specialisation on particular microhabitats or land cover types (Judd \& Horwitz, 2003; Paoletti et al., 2007; David \& Handa, 2010), for example as refugia from seasonal periods of dryness, may represent more critical niche dimensions than diet breadth for saprophagous macro-arthropods.

Millipedes (Diplopoda), woodlice (Crustacea: Oniscidea) and other non-social saprophagous macroarthro- 
pods are classified as litter transformers (Lavelle et al., 1997; Wardle, 2002) and represent key regulators of plant litter decomposition within ecosystems (David \& Handa, 2010). They make a major contribution to invertebrate biomass within most ecosystems (Paoletti et al., 2007) and their sensitivity to pesticide applications, land use changes and heavy metal contamination (for some species) make them invaluable bioindicators (Paoletti \& Hassall, 1999; Souty-Grosset et al., 2005). There is evidence (reviewed in David \& Handa, 2010) that these species may already be responding to global changes such as warming, drought and habitat destruction. Warming for example is expected to increase the rate of population growth in some temperate species but will interact with other changes such as elevated $\mathrm{CO}_{2}$ levels that largely reduce leaf litter quality (with knock-on impacts on fertility) (David \& Gillon, 2009). Our understanding of underlying mechanisms and ability to generalise these trends is hampered by a lack of ecological and physiological data for many species (David \& Handa, 2010).

Here we investigate relationships between traits and distribution patterns (range size and fill) using woodlice as an example taxon of saprophagous arthropods. The dataset was collated through the volunteer-led NonMarine Isopod Recording Scheme, comprising biological records across the British Isles that include detailed recording of fine-scale habitat use for locations in which species were found. We examine the relationship between traits (life-history traits and habitat use) and distribution patterns in woodlouse (using multivariate methods that account for variation in recording intensity between species).

\section{METHODS}

\section{Species data}

Woodlouse taxonomy followed the classification adopted by the Isopod Recording Scheme within the British Myriapod and Isopod Group (Gregory, 2009). Haplophthalmus mengei (Zaddach, 1844), Trichoniscus pusillus Brandt 1833, Oniscus asellus Linnaeus 1758 are all species groups of two or more closely related species that are not routinely distinguished by recorders and were thus treated as one species in the analysis. Five alien species were excluded from the analysis since they are largely sub-tropical and tropical species, restricted to glass-houses, garden centres or botanic gardens. These were Cordioniscus stebbingi (Patience, 1907), Metatrichoniscoides leydigii (Weber, 1880), Reductoniscus costulatus Kesselyak, 1930, Styloniscus mauritiensis (Barnard, 1936), Trichorhina tomentosa (BuddeLund, 1893).

Data on the location of woodlice, precise to the nearest $10 \mathrm{~km}$ or finer resolution and dated between 1968 (start date of scheme) and 2008 were obtained from the Isopod Recording Scheme (84,532 records in total). The Isopod Recording Scheme is led by a volunteer scheme organiser, with taxonomic expertise, who ensures the quality of data using voucher specimens or acceptance of records from trusted sources (known taxonomic experts). Additional validation checks are applied to the data, to ensure correct dates and localities, through an automated querying system within the database to identify records that do not comply to specified criteria (for example, location not in known range). Out of all the $10 \times 10-\mathrm{km}$ Ordnance Survey grid squares ("hectads") in Britain, after Pocock et al.
(2006), the study area was restricted to mainland Britain and the near shore islands of the Inner Hebrides, Isle of Wight and Anglesey (range in eastings; 50,000-650,000; range in northings; 10,000-105,000). Using a bespoke R script, the distance between the coordinates of each record (Eastings and Northings) of a particular species and the centre coordinates of each of the the study area squares was calculated to determine which square each record was closest to and to summarise in which squares each species was present or absent. The final dataset consisted of 33 species, recorded from between 5 (Metatrichoniscoides celticus Oliver \& Trew, 1981) and 2381 (Oniscus asellus) $10-\mathrm{km}$ squares of the $277910-\mathrm{km}$ squares available across the study region (mean \pm s.e. $=504 \pm 121)$.

\section{Measuring range characteristics}

For each species, the range size was measured as the proportion of $10 \mathrm{~km}^{2}$ grid squares (of the 2779 available in the study area), that were occupied and logit-transformed. The logit transformation is routinely used to normalise range size datasets that have a large range size distribution (Williamson \& Gaston, 1999). Aggregation was measured in two ways and represents the degree to which occupied squares are clustered together across the range. Firstly, after Peitgen et al. (1992) and Hartley et al. (2004), $\mathrm{D}_{10-100}$ was calculated from the slope of a linear $\log$-log regression of the area occupied against scale $\left(\log _{10}\right.$ side of grid cell), at resolutions of 10 and $100 \mathrm{~km}$ (no intermediatesized squares were included).

$$
D_{10-100}=\frac{2-\left[\log _{10}\left(A O O_{10}\right)-\log _{10}\left(A O O_{100}\right)\right]}{\left[\log _{10}(100000)-\log _{10}(10000)\right]}
$$

where $\mathrm{AOO}_{10}$ is number of $10 \mathrm{~km}^{2}$ grid cells occupied multiplied by the area of a $10 \mathrm{~km}$ square (i.e. $10,000^{2}$ ) and $\mathrm{AOO}_{100}$ is number of $100 \mathrm{~km}^{2}$ grid cells occupied. $\mathrm{x}$ the area of a $100 \mathrm{~km}$ square (i.e. $100,000^{2}$ ).

The index ranges from 0 for no aggregation, where each occupied $10 \mathrm{~km}$ square occurs alone in a $100 \mathrm{~m}$ squareand 2 for perfect aggregation where all the $10 \mathrm{~km}$ squares within a 100 $\mathrm{km}$ square are occupied. The second method was developed by Condit et al. (2000) and previously applied by Wilson et al. (2004) to quantify range aggregation in butterflies and plants at a $10 \mathrm{~km}$ grid scale. The method was modified here to account for the fact that some squares on the coast will be surrounded by both land and sea, reducing the maximum potential level of aggregation around such squares. For each species, the absolute number of presence records in circular radii of 10 and $50 \mathrm{~km}$ around each individual $10 \mathrm{~km}$ square was calculated and divided by the actual number of land records found within a circle of that size. These proportions per square were then averaged across the study area to give each species a value of aggregation, $\mathrm{D}_{\mathrm{y} 10 \mathrm{~km}}$ between 0 and 1 . From previous studies, it is known that aggregation is highly dependent on range size (Pocock et al., 2006). $\mathrm{AOO}_{10}$ (log-transformed) was therefore included as a covariate in all models testing effects on $D_{10-100}$, $D_{\mathrm{y} 10 \mathrm{~km}}$ and $\mathrm{D}_{\mathrm{y} 50 \mathrm{~km}}$ to evaluate whether trait variables make species more or less aggregated than expected from their range size.

\section{Selection of life history and ecological traits}

Traits (Table 1) that might explain range characteristics were selected a priori on the basis of evidence from previous studies.

(i) Morphological traits - body size. Woodlice range in length from $2 \mathrm{~mm}$ to $30 \mathrm{~mm}$. Though large body size is cited amongst the indicator traits of vulnerability to habitat fragmentation along with low motility and low population abundance (Ewers \& Didham, 2006) - it is also a characteristic of isopods with higher fertility (Sutton et al., 1984) and desiccation resistance (Tsai et al., 1998). Given that woodlice seem to be able to per- 
TABLE 1. Traits used as predictors in the analysis of range structure characteristics of woodlice. Species values for traits are tabulated in the supplementary information and were derived from the species accounts in Gregory (2009).

\begin{tabular}{|c|c|}
\hline Trait & Description and source \\
\hline Body size (mm) & Body size in $\mathrm{mm}$ from distinctive features section of species account (log-transformed) \\
\hline $\begin{array}{l}\text { Broad-scale } \\
\text { habitat use }\end{array}$ & $\begin{array}{l}\text { Categorical variable indicating range of EUNIS } 2 \text { habitats used according to Habitat section of species account } \\
\text { coded as follows. Species uses } A=0-2 \text { habitat, } B=3-4 \text { habitats, } C=5 \text { or more habitats }\end{array}$ \\
\hline Fully-managed & $\begin{array}{l}\text { Binary variable indicating whether the species uses habitats representative of Artificial or Agricultural habitats } \\
\text { in EUNIS } 1 \text { categorisation. }\end{array}$ \\
\hline Grassland & $\begin{array}{l}\text { Binary variable indicating whether the species uses habitats representative of Grassland habitats in EUNIS } 1 \\
\text { categorisation. }\end{array}$ \\
\hline Woodland & $\begin{array}{l}\text { Binary variable indicating whether the species uses habitats representative of Woodland habitats in EUNIS } 1 \\
\text { categorisation. }\end{array}$ \\
\hline $\begin{array}{l}\text { Fine-scale } \\
\text { habitat use }\end{array}$ & $\begin{array}{l}\text { From section E of record cards submitted to the Isopod recording scheme between } 1962 \text { and 1982, use of } 17 \\
\text { microsites scored across } 23360 \text { records }\end{array}$ \\
\hline Synanthropic & $\begin{array}{l}\text { Categorical variable coding the degree to which species is associated with humans in habitat choice as follows: } \\
\text { No = not synanthropic occurring in natural habitats, Moderately = occur in both managed and natural habitats, } \\
\text { Strongly = occur predominantly in fully managed habitats. }\end{array}$ \\
\hline Recording intensity & Average number of records per square of distribution \\
\hline
\end{tabular}

sist in quite small fragments of habitat (Bolger et al., 2000), overall we expected range size and fill to increase with increasing body size due to increased fecundity and desiccation resistance.

(ii) Ecological traits - habitat use. The diversity of habitat used by woodlice was scored in terms of broad habitat classes and the fine scale microsites such as litter, dead wood and stones occupied within these broad habitats. Broad scale habitat was quantified as the number of EUNIS level 2 habitats used by a species. The EUNIS (European Nature Information System) habitat classification (Davies et al., 2004) is a pan-European classification of terrestrial, freshwater and marine habitats that has been developed for the European Environment Agency by the European Topic Centre on Biological Diversity (ETC/BD). The latest version can be accessed at http://eunis2.eea.eu.int/. Also scored for each species was the use of fully managed habitats (urban and agricultural), use of woodland and grassland habitats. Due to the procedure of noting microsites used by woodlice recorded on the standardised recording cards submitted to the Isopod Recording Scheme, fine scale habitat use could be quantified as the number of microsites used across records of a species (Table 2 specifies range of potential microsites). As found for other arthropod groups (Brandle et al., 2002), we predict that range size will increase with the diversity of broad-scale and fine-scale habitats used by species. Since isopods in Britain tend to be more abundant (higher numbers of individuals) in grassland than woodland (Davis \& Sutton, 1978) one might expect grassland species to show larger range sizes and aggregation. Additionally, given the extent of land conversion in Britain to intensive agriculture and urban areas, we predict that species using such synanthropic or fully managed habitats will be more widespread than species that do not use these habitats (Vilisics et al., 2007).

Recording intensity represents a sampling constraint that necessitates consideration. Some species may be relatively under-recorded and the extent of under-recording may also depend on other traits such as habitat use (with soil-dwelling species being under-recorded), and body size (small sized species being difficult to find). Though it is difficult to eliminate this bias in our analyses, we constructed a measure of recording intensity that was independent of range size namely the average number of records per $10 \mathrm{~km}$ square of distribution.
Species values for traits are tabulated in the supplementary information and were derived from the species accounts in Gregory (2009). Additional body size information was obtained from Harding \& Sutton (1985) for Halophiloscia couchii (Kinahan, 1858). For species groups, closely related species that can only be separated by microscopic examination of a male specimen (Gregory, 2009), trait values were taken for the species that made up the largest proportion of records.

\section{Analysis of relationships between range characteristics and traits}

The relationships between range characteristics and traits were investigated using Generalised Linear Models (McCullagh \& Nelder, 1989) with a gaussian error structure implemented in $\mathrm{R}$ version 2.10.1 (R Development Core Team, 2010). We predicted a priori that fine-scale and broad-scale habitat use would be highly correlated and were interested in the relative performance of these measures as predictors of range size and aggregation. Thus two pools of candidate predictors were constructed with seven predictors each, one containing broad-scale habitats, body size, recording intensity and four other habitat predictors (grassland, fully managed, woodland and synanthropic habitats) and one containing fine-scale habitats, body size, recording intensity and the four habitat predictors.

To deal with possible collinearity between predictors, pairwise associations between the variables were examined prior to model fitting using non-parametric tests with sequential Bonferroni correction (Quinn \& Keough, 2002). A hierarchical partitioning analysis (McNally, 2002) was also performed with all seven predictors in each pool, using the hier.part package (note that phylogenetic correction is not feasible in hierarchical partitioning). Hierarchical partitioning is especially suitable for dealing with collinearity among variables, as it disentangles each variable-specific effect from its interactions with all other variables considered. From this analysis, probability of independent contribution of the predictors was assessed with z-scores obtained using 10,000 repeated randomizations (with the rand.hp function and a $\mathrm{R}^{2}$ goodness-of-fit measure). Only those variables that made a significant independent contribution were retained in the predictor pool. Every possible model combination (all subsets regression) of the remaining variables was fitted to the data and the fit of the competing models compared using Akaike's Information Criterion, adjusted for small sampled sizes $\left(\mathrm{AIC}_{\mathrm{c}}\right)$, to ascertain the most parsimonious model. 
TABLE 2. Microsites scored for woodlice species across (for 23,360 records submitted between 1938 and 1982).

\begin{tabular}{cccc}
\hline Code & Microsite description & \multicolumn{2}{c}{ Frequency and \% of } \\
records across species
\end{tabular}

To account for the effect of phylogenetic relationships between species on the predictors, we also fitted phylogenetic generalized least-square (PGLS) (Freckleton et al., 2002) models for each variable combination implemented in $\mathrm{R}$ using the ape package (Paradis et al., 2004). The expected covariance between species was calculated on the basis of the taxonomy set out by Gregory (2009) and arbitrary branch lengths were assumed. A Brownian motion model of evolution was assumed and lambda, the parameter reflecting the degree of phylogenetic autocorrelation in the model, was optimised (Pagel, 1999). Selection between the PGLS regression models and ordinary least squares (OLS) regression models for range characteristics was again made on the basis of AICc. This allowed for comparison between models with different numbers of parameters and therefore selection of the minimum adequate model (MAM) amongst all possible alternatives. We used adjusted deviance explained (\% variance) to compare observations and predictions (Weisberg, 1980).

\section{RESULTS}

\section{Correlations between trait variables}

The species that used a wide range of broad-scale habitats also tended to use a wide range of fine-scale habitats - namely microsites within these broad habitats (Spearman's rho $=0.603, p=0.0002, p_{\text {corr }}=0.008$ ). Species scored as occurring in fully managed EUNIS 2 habitats tended to also inhabit a larger range of broad-scale (Kruskal-Wallis $\mathrm{H}=6.72$, d.f. $=2, \mathrm{p}_{\text {corr }}=0.0095$ ) and fine-scale habitats $\left(\mathrm{H}=11.24\right.$, d.f. $\left.=2, \mathrm{p}_{\text {corr }}=0.0008\right)$ overall. Species living in woodlands also tended to be present in grasslands and vice versa (Fisher's exact test; $p$ $<0.0001)$. Almost all species using grassland were moderately synanthropic $\left(13 / 18\right.$ species, tau $=-0.511, \mathrm{p}_{\text {corr }}=$ 0.007). The diversity of habitats used at both fine-scale (Spearman's rho $=0.512, \mathrm{p}_{\text {corr }}=0.002$ ) and broad-scales (Spearman's rho $=0.402, \mathrm{p}_{\text {corr }}=0.02$ ) was correlated with recording intensity.

\section{Relationship between traits and range size}

From the broad-scale predictor set, three variables made a significant independent contribution to explaining variance in range size between woodlouse species. These were the number of broad-scale habitats, use of fully managed habitats and recording intensity. Only recording intensity and the use of fully managed habitats were retained in the minimum adequate model (Table 3a) and together explained $61 \%$ of the variation in range size. Range size increased with recording intensity depending on the use of fully managed habitats (Table 4a, Fig. 1b), and species not using fully managed habitats were generally restricted to range sizes of less than $50010-\mathrm{km}$ squares (Fig. 1c). Examining the increase in AICc when each variable in the model is dropped $(\triangle \mathrm{AICc}$ in Table 4a) reveals that recording intensity was the most important predictor in this model.

From the fine-scale predictor set, three variables made a significant independent contribution in explaining variance in range size between species. These were the number of fine-scale habitats, recording intensity and use of fully managed habitats. Of these, only the number of fine-scale habitats and recording intensity were retained

TABLE 3. Top three trait-based models predicting range size of woodlice.

\begin{tabular}{|c|c|c|c|c|}
\hline \multirow{2}{*}{ Variables in the model } & \multicolumn{2}{|c|}{ OLS model } & \multicolumn{2}{|c|}{ PGLS model } \\
\hline & $\mathrm{D}^{2}\left(\operatorname{Adj}-\mathrm{D}^{2}\right)$ & $\mathrm{AICc}$ & Pagels's $\lambda$ & AICc \\
\hline \multicolumn{5}{|l|}{ (a) predictor pool with broad-scale habitat use } \\
\hline Recording intensity + Artific & $0.606(0.579)$ & 119.4 & 0.000042 & 119.6 \\
\hline EUNIS 2 habitats used + recording intensity + Artific & $0.629(0.591)$ & 120.0 & 0.000069 & 121.3 \\
\hline EUNIS 2 habitats used + recording intensity & $0.546(0.516)$ & 124.1 & 0.000066 & 124.2 \\
\hline \multicolumn{5}{|l|}{ (b) predictor pool with fine-scale habitat use } \\
\hline Microsites used + recording intensity & $0.880(0.872)$ & 80.1 & 0.000066 & 80.3 \\
\hline Microsites used + Artific + recording intensity & $0.880(0.868)$ & 82.7 & 0.000066 & 83.9 \\
\hline Microsites used + Artific & $0.885(0.849)$ & 86.3 & 0.000066 & 86.5 \\
\hline
\end{tabular}

No $\lambda$ values were significantly different from 0 in likelihood ratio tests, indicating no significant phylogenetic autocorrelation in any model. Artific. $=$ use of EUNIS 2 habitats which are fully managed. 
TABLE 4. Coefficients for predictors in the minimum adequate model for range size.

\begin{tabular}{|c|c|c|c|c|c|}
\hline & Coeff. & s.e. & $\mathrm{t}$ & p-value & $\triangle \mathrm{AICc}$ \\
\hline \multicolumn{6}{|c|}{ (a) predictor pool with broad-scale habitat use } \\
\hline (Intercept) & -6.08 & 0.58 & -10.49 & $<0.00001$ & - \\
\hline Recording intensity & 0.86 & 0.17 & 5.04 & $<0.00001$ & 17.8 \\
\hline as.factor(Artific.) 1 & 1.60 & 0.52 & 3.08 & 0.004 & 6.6 \\
\hline \multicolumn{6}{|c|}{ (b) predictor pool with fine-scale habitat use } \\
\hline (Intercept) & -7.13 & 0.34 & -20.8 & $<0.00001$ & - \\
\hline Microsites used & 0.39 & 0.04 & 10.0 & $<0.00001$ & 45.9 \\
\hline Recording intensity & 0.27 & 0.11 & 2.6 & 0.015 & 4.22 \\
\hline
\end{tabular}

in the minimum adequate model (Table $3 \mathrm{~b}$ ) and together explained $88 \%$ of the variation in range size (Fig. 2). The number of fine-scale habitats used was the most important predictor in the model ( $\triangle \mathrm{AICc}$ in Table $4 \mathrm{~b})$. Range size increased with the breadth of fine-scale habitats used by a species (Table 4b) and species occupying less than ten fine-scale habitats were generally restricted to range sizes of less than 500 10-km squares (Fig. 1a). Overall, finescale habitats explained around $25 \%$ more variation in range size than the best model including broad-scale habitats $(\triangle \mathrm{AICc}=40$ between the fine-scale and broad-scale model). There was no evidence of phylogenetic autocorrelation in either of the minimum adequate models for range size since lambda values did not differ significantly from zero and PGLS models did not produce lower values of AICc than OLS models.

Species that were observed to be much rarer than predicted from minimum adequate trait models were Haplophthalmus mengei, Platyarthrus hoffmannseggii Brandt 1833 and Trichoniscus provisorius Racovitza 1908. Species that were observed to be more widespread than predicted from their habitat use included Trachelipus rathkii Brandt 1833, Porcellio dilatatus Brandt 1833 and Armadillidium vulgare Latreille 1804.

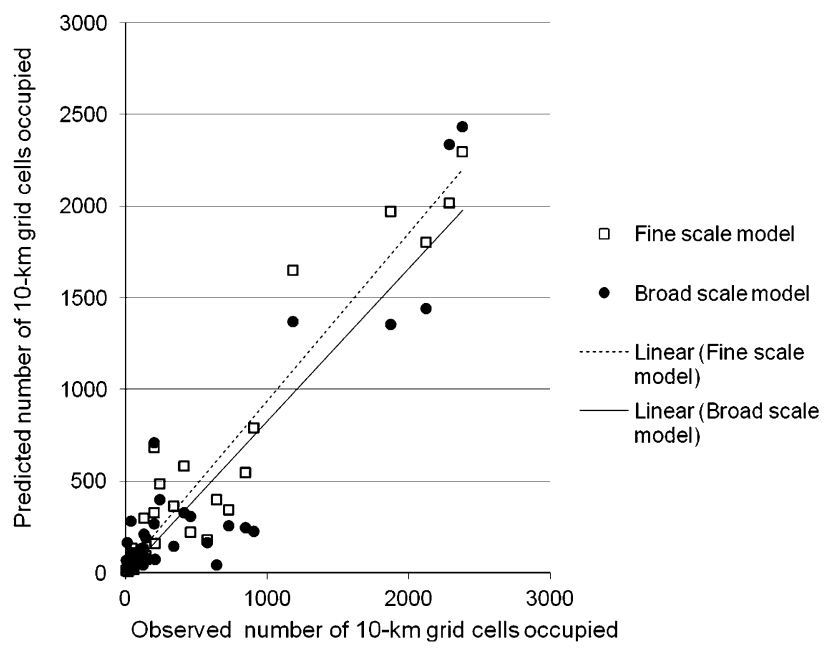

Fig. 2. Predicted versus observed range size of woodlice (expressed as number of $10 \mathrm{~km}$ squares in Britain and nearshore islands occupied) for the broad scale model (EUNIS 2 habitat use + recording intensity + fully managed, closed circles and solid regression line) and the fine scale model (microsite use + recording intensity, open squares and dashed regression line).

\section{Selection of life history and ecological traits}

As expected from previous aforementioned studies of range characteristics in other taxa, area of occupancy at a $10 \mathrm{~km}$ resolution, i.e. $\log _{10}\left(\mathrm{AOO}_{10}\right)$, accounted for a large proportion of the variation in aggregation across species (Table 5 whereby $\mathrm{D}_{10-100}: \mathrm{F}_{1,31}=279.6, \mathrm{p}<0.0001 ; \mathrm{D}_{\mathrm{y} 10}$ : $\left.\mathrm{F}_{1,31}=114.9, \mathrm{p}<0.0001 ; \mathrm{D}_{\mathrm{y} 50}: \mathrm{F}_{1,31}=113.4, \mathrm{p}<0.0001\right)$. That is species with small areas of occupancy were more densely packed within their range of occupancy and so had aggregation estimates ranging from $87-92 \%$.

Hierarchical partitioning analysis suggested that, in addition to area of occupancy, use of grassland habitats, and recording intensity all made independent contributions to variance. The variance was also explained by number of broad-scale and fine-scale habitats depending on which aggregation measure was under consideration. The minimum adequate model for $\mathrm{D}_{10-100}$
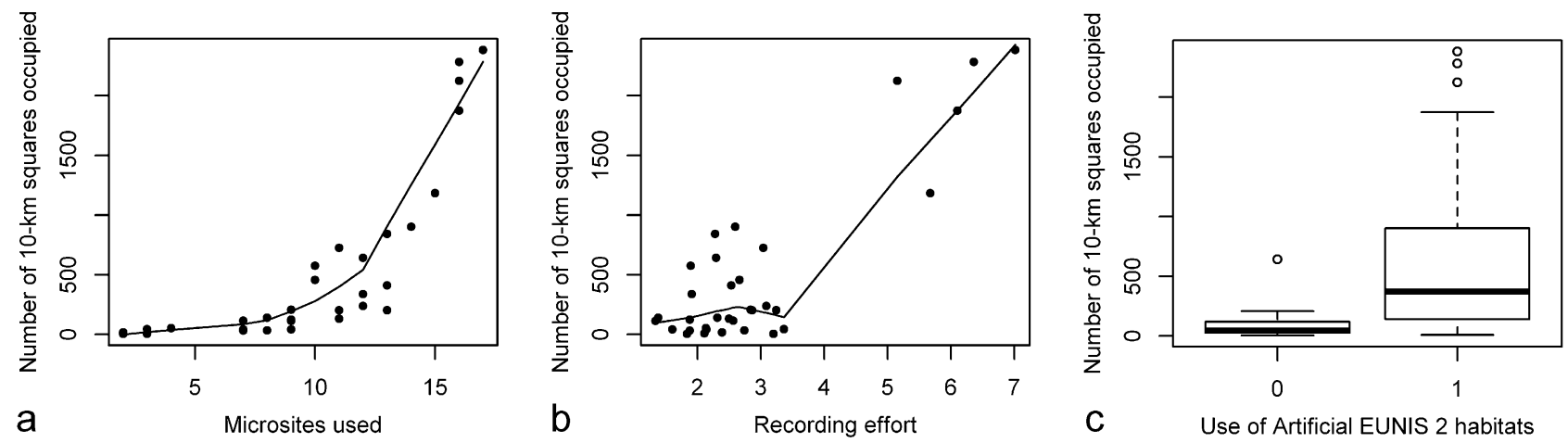

Fig. 1. Range size versus key explanatory trait predictors [fine-scale habitat use (microsites used), recording effort (recording intensity) and broad-scale habitat use (use of artificial EUNIS 2 habitats)]. Range size is displayed as the number of occupied 10-km squares in Britain and nearshore islands. Solid lines on panels (a) and (b) are lowess (locally-weighted polynomial regression) smoothers of the relationship between the trait and range size. In panel (c) the dark line across the box indicates the group median whilst the whiskers indicate the range of values for the group. 


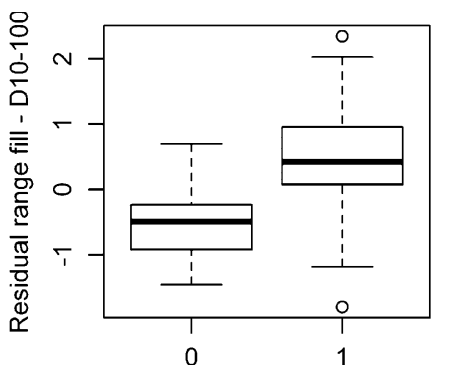

a Use of Grassland EUNIS 2 habitats

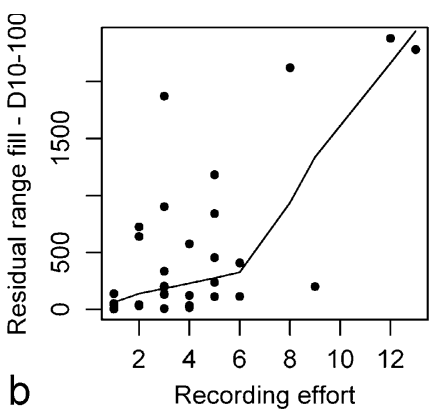

b

Recording effort

Fig. 3. Residual aggregation versus key explanatory trait predictors (a) use of Grassland EUNIS 2 habitats (broad-scale habitat) (b) recording effort (recording intensity). In each case residuals are standardised residuals derived from a linear regression of $\mathrm{D}_{10-100}$ on $\log _{10}\left(\mathrm{AOO}_{10}\right)$ In panel (a) the dark line across the box indicates the group median whilst the whiskers indicate the range of values for the group. The solid line on panel (b) is a lowess (locally-weighted polynomial regression) smoother of the relationship between recording intensity and residual aggregation.

included area of occupancy, and use of Grassland EUNIS 2 habitats (row 3, Table 5a) whilst the models for $\mathrm{D}_{\mathrm{y} 10}$ and $\mathrm{D}_{\mathrm{y} 50}$ included area of occupancy and recording intensity (row 1 , Tables $5 \mathrm{~b}$ and $5 \mathrm{c}$ ). Species that had been sampled more intensively and/or used Grassland EUNIS 2 habitats had filled a larger proportion of their ranges according to this measure (Table 6, Fig. 3). There was no evidence of phylogenetic autocorrelation in any of the minimum adequate models for aggregation since lambda values did not differ significantly from zero and PGLS models did not produce lower values of AICc than OLS models.

Species that were observed to fill a smaller proportion of their ranges than would be predicted from trait-based models included Trichoniscus provisorius and Hap- lophthalmus mengei. In contrast, Oritoniscus flavus Budde-Lund, 1906 and T. rathkii filled a greater proportion of their ranges than predicted by the final models.

\section{DISCUSSION}

This study represents the first attempt to identify ecological correlates of range characteristics for a group of macro-arthropods that play a critical role in decomposition and nutrient recycling within ecosystems. Links between diversity and ecosystem function in soil systems are unclear, although the diversity of litter species and decomposer organisms can profoundly influence litter decomposition and nutrient mineralisation and have feedback effects on plant growth and community composition (Hättenschwiler et al., 2005). Therefore, understanding

TABLE 5. Top three trait-based models predicting aggregation measures $\left(\mathrm{D}_{10-100}, \mathrm{D}_{\mathrm{y} 10}\right.$ and $\left.\mathrm{D}_{\mathrm{y} 50}\right)$ of woodlice contrasted against a model containing only area of occupancy $\left(\log _{10}(\mathrm{AOO} 10)\right.$.

\begin{tabular}{|c|c|c|c|c|}
\hline \multirow{2}{*}{ Variables in the model } & \multicolumn{2}{|c|}{ OLS model } & \multicolumn{2}{|c|}{ PGLS model } \\
\hline & $\mathrm{D}^{2}\left(\mathrm{Adj}-\mathrm{D}^{2}\right)$ & $\mathrm{AICc}$ & Pagels's $\lambda$ & $\mathrm{AICc}$ \\
\hline \multicolumn{5}{|l|}{ (a) $\mathrm{D}_{10-100}$} \\
\hline as.factor $($ Grass $)+\log 10\left(\mathrm{~A} 00_{10}\right)+$ recording intensity & $0.938(0.931)$ & -38.2 & 0.000066 & -34.9 \\
\hline Microsites used + as.factor $($ Grass $)+\log 10\left(\mathrm{~A} 00_{10}\right)+$ recording intensity & $0.939(0.931)$ & -36.4 & 0.000066 & -32.8 \\
\hline as.factor(Grass $)+\log 10\left(\mathrm{A00}_{10}\right)$ & $0.929(0.924)$ & -36.3 & 0.000066 & -35.2 \\
\hline $\log 10\left(\mathrm{~A} 00_{10}\right)$ & $0.900(0.897)$ & -27.6 & 0.000066 & -26.2 \\
\hline \multicolumn{5}{|l|}{ (b) $\mathrm{D}_{\mathrm{y} 10}$} \\
\hline Recording intensity $+\log 10\left(\mathrm{A00}_{10}\right)$ & $0.878(0.871)$ & -61.2 & 0.000066 & -61.0 \\
\hline EUNIS2 habitats used + as.factor(Grass $)+\log 10\left(\mathrm{~A} 00_{10}\right)+$ recording intensity & $0.893(0.882)$ & -60.8 & 0.000066 & -57.6 \\
\hline as.factor(Grass $)+\log 10\left(\mathrm{~A} 00_{10}\right)+$ recording intensity & $0.884(0.876)$ & -60.7 & 0.000066 & -58.9 \\
\hline $\log 10\left(\mathrm{~A} 00_{10}\right)$ & $0.787(0.781)$ & -45.1 & 0.000066 & -46.1 \\
\hline \multicolumn{5}{|l|}{ (c) $\mathrm{D}_{\mathrm{y} 50}$} \\
\hline Recording intensity $+\log 10\left(\mathbf{A 0 0}_{10}\right)$ & $0.919(0.913)$ & -69.1 & 0.000066 & -69.0 \\
\hline Microsites used + recording intensity $+\log 10\left(\mathrm{~A} 00_{10}\right)$ & $0.926(0.919)$ & -69.9 & 0.000066 & -65.9 \\
\hline EUNIS2 habitats used + recording intensity $+\log 10\left(\mathrm{~A} 00_{10}\right)$ & $0.921(0.912)$ & -67.2 & 0.000066 & -68.6 \\
\hline $\log 10\left(\mathrm{~A} 00_{10}\right)$ & $0.786(0.778)$ & -39.4 & 0.000066 & -40.4 \\
\hline
\end{tabular}

Models given in bold text are the minimum adequate model in each case. None of the $\lambda$ values were significantly different from 0 in likelihood ratio tests, indicating no significant phylogenetic autocorrelation in any model. Grass = use of Grassland EUNIS 2 habitats. 
TABLE 6. Coefficients for predictors in the minimum adequate model for aggregation $\left(\mathrm{D}_{10-100}, \mathrm{D}_{\mathrm{y} 10}\right.$ and $\left.\mathrm{D}_{\mathrm{y} 50}\right)$.

\begin{tabular}{|c|c|c|c|c|c|}
\hline & Coeff. & s.e. & $\mathrm{t}$ & p-value & $\triangle \mathrm{AICc}$ \\
\hline \multicolumn{6}{|l|}{ (a) $\mathrm{D}_{10-100}$} \\
\hline (Intercept) & -1.44 & 0.14 & -10.48 & $<0.00001$ & - \\
\hline $\log _{10}\left(\mathrm{AOO}_{10}\right)$ & 0.54 & 0.03 & 15.73 & $<0.00001$ & 71.0 \\
\hline as.factor(Grass) 1 & 0.17 & 0.05 & 3.45 & 0.0017 & 8.6 \\
\hline \multicolumn{6}{|l|}{ (b) $D_{y 10}$} \\
\hline (Intercept) & -0.67 & 0.09 & -7.12 & $<0.00001$ & - \\
\hline $\log _{10}\left(\mathrm{AOO}_{10}\right)$ & 0.22 & 0.03 & 8.47 & $<0.00001$ & 37.9 \\
\hline Recording intensity & 0.06 & 0.01 & 4.74 & 0.00005 & 16.0 \\
\hline \multicolumn{6}{|l|}{ (c) $\mathrm{D}_{\mathrm{y} 50}$} \\
\hline (Intercept) & -0.85 & 0.08 & -10.22 & 0.00000 & - \\
\hline $\log 10\left(\mathrm{AOO}_{10}\right)$ & 0.22 & 0.02 & 9.63 & 0.00000 & 44.0 \\
\hline Recording intensity & 0.08 & 0.01 & 7.03 & 0.00000 & 29.7 \\
\hline
\end{tabular}

correlates of rarity for these taxa is imperative given their important functional traits and sensitivity to land use and climate changes (David \& Handa, 2010).

\section{Range characteristics and habitat breadth}

Our result indicating that species with a wide habitat breadth are more widely distributed is consistent with findings for herbivorous and predatory arthropod groups (Brandle et al., 2002; Kotze et al., 2003; Comont et al., 2012) that generally have higher levels of dietary specialisation than saprophagous groups (Maraun et al., 2003) Understanding which metrics of habitat breadth (e.g. microsite or prey use versus broad habitat use) underpin range size at different scales, and why, is key therefore to predicting rarity across a range of taxa. Sometimes the direction of causality between range size and habitat breadth is unclear because measurement of ecological specialisation is not independent of abundance or range size (Hanski et al., 1993) and widespread, abundant species are often studied more intensively than rare species. We incorporated a species-specific measure of recording intensity from recording history into our analysis and found independent effects of fine-scale habitat breadth, giving us greater confidence that habitat breadth is positively correlated with range size for woodlice. Recording intensity had some impact on both range size and aggregation however, with species sampled more intensively observed to have larger ranges and fill a larger proportion of these ranges than species sampled less intensively.

According to models for one of the aggregation measures $\left(D_{10-100}\right)$, all species that exploit grassland, either as specialists or as one habitat of a generalist species, were also found to have filled a larger proportion of their ranges than species that did not use grassland. Species of woodlice that utilise grassland will obviously benefit from the large proportion of grassland (around 31\%) in the landscape compared to woodland [around 10\%, CEH Landcover Map 2000 (Fuller et al., 2005)] and the overall increase in area of intensively managed grassland over the last twenty years (Smart et al., 2010). Isopods also reach high densities in grassland e.g. up to 3000 individuals $\mathrm{m}^{-2}$ in calcareous grasslands (Paoletti \& Hassall, 1999), possibly providing larger source populations from which to disperse into adjacent habitat. Our understanding of factors driving aggregation in saprophagous macroarthropods would be enhanced with detailed information on species' habitat preferences collected in a standardised way across species. Two of the species found to fill a greater proportion of their ranges than would be predicted from recording intensity or grassland habitat use were Oritoniscus flavus and Trachelipus rathkii, both are species that are common across habitats within river catchments in Britain (Gregory, 2009).

The considerably higher accuracy of predictions of range size based on fine-scale rather than broad-scale measurements of habitat breadth (Adjusted- $\mathrm{D}^{2}$ of 0.88 versus 0.60 and $\triangle \mathrm{AIC}$ of $\sim 20$ ) illustrates the value of coupling biological recording with records of habitat for studying macro-ecological processes. This has been demonstrated repeatedly for charismatic, well-studied taxa such as birds (Gregory \& Gaston, 2000) and butterflies (Oliver et al., 2009) but is perhaps even more critical for understanding patterns in taxa, such as saprophagous macroarthropods, that have been subject to only a few, short term ecological studies on a limited number of species (David \& Handa, 2010) with little consideration of macro-ecological patterns (Decaens, 2010).

Habitat breadth and use are key determinants of range size and fill in woodlice providing further evidence that saprophagous macroarthropods are sensitive to land use (Judd \& Horwitz, 2003; Dauber et al., 2005) and land use changes (Tajovsky, 2001). This result adds support to the suggestion of David \& Handa (2010) that preserving a degree of land cover heterogeneity will be more favourable to macro-arthropod diversity than uniform habitats covering large areas. Dauber et al. (2005) for example, found that even at local scales, land use particularly affected distribution patterns of woodlice, whereas ants and rove beetles were more strongly affected by other habitat characteristics (insolation and soil characteristics).

\section{Other potential correlates of rarity in saprophagous macro-arthropods}

It is particularly enlightening to examine characteristics of species for which range charactersistics are under- or over-estimated because they could provide some indication of key niche dimensions or traits that may be critical for understanding macro-ecological processes in woodlice and other saprotrophic macroarthropods. In addition, correlates of rarity are likely to be scale-dependent (Brandle et al., 2002). For example, the distribution of one of the species found to be rarer than predicted, Platyarthrus hoffmannseggii, is known to be limited at fine spatial scales by their association with particular ant species (Cawley, 2001); a species interaction that is not reflected in our index of fine-scale habitat use. Trichoniscus provisorius, also observed to be less widespread than predicted from recorded habitat use, is probably limited by its 
thermal tolerance rather than habitat type, favouring high level of insolation and south-facing slopes on the edge of its range in Britain (Gregory, 2009). Additional information on the ecophysiological tolerance of different woodlouse species would certainly enhance our understanding of their distribution patterns and responses to environmental changes but such data are currently available for only a limited subset of species within narrow geographic ranges (David \& Handa, 2010). Though saprophagous macroarthropods are expected to have a much lower degree of diet specialisation than herbivorous or predatory arthropods, there is substantial evidence that their life-history parameters and fine-scale distribution and biomass patterns are influenced by food quality, namely litter quality and coarse wood density (Rushton \& Hassall, 1987; Hassall et al., 2002; Gongalsky et al., 2005; Topp et al., 2005; David \& Handa, 2010).

Dispersal ability has been found to be a key determinant of range size for many taxa, particularly those that are highly motile (Beck \& Kitching, 2007; Rundle et al., 2007). However, dispersal ability is general thought to be low for saprophagous macroarthropods, although many species have been found colonising post-mining rehabilitation sites (Tajovsky, 2001). It appears that the extent of local dispersal is unstudied for most woodlouse species but evidence from genetic studies of cosmopolitan species suggests that dispersal over longer distances is humanmediated (Wang \& Schreiber, 1999). As such, particular habitat use traits such as synanthropy or use of fully managed habitats may predispose species to long distance dispersal and range extension. Indeed, two species found to be more widespread than predicted from its fine-scale habitat use, Porcellio dilatatus and Armadillidium vulgare, are particularly noted as synanthropic species (Gregory, 2009).

We have examined distribution patterns (aggregation and size) for woodlice in Britain and for some species this represents only a subset of their entire global distribution. Geographical constraints and, indeed, under-recording could cause inaccuracies in the distribution patterns observed (Beck \& Kitching, 2007). Therefore, precise predictions of range characteristics cannot necessarily be expected from species-specific traits across all species within a specific taxon (Beck \& Kitching, 2007). In our study two of the species that were observed to be rarer than would be predicted from their habitat breadth, namely Platyarthrus hoffmannseggii and Trichoniscus provisorius, are on the edge of their distribution ranges in Britain and could be constrained by suboptimal environmental conditions.

\section{CONCLUSION}

The importance of saprophagous arthropods in providing key ecosystem services is being increasingly recognised. However, although litter transformation is a pivotal ecosystem service, our understanding of the processes driving macro-ecological patterns in soil biota, including saprophages, is extremely limited (Decaens et al., 2010; David \& Hanada, 2010). Our findings that spe- cialised species (low habitat breadth) have restricted ranges suggest that habitat heterogeneity is critical for maintaining the distributions and diversity of woodlice in Britain. David \& Handa (2010) also noted the importance of habitat heterogeneity as good option for conservation of woodlice, even at the cost of some fragmentation. We further highlight the need to consider the ecological requirements of saprophagess such as woodlice as conservation priorities alongside charismatic taxa such as butterflies.

The rarer species for which our analyses did not accurately explain range structure could be the emphasis of future recording activity and research particularly with respect to the effects of climate change on species at the edge of their core range. This is particularly critical if such nationally rare species play a locally important role, where they are abundant, in ecosystem functions such as litter decomposition. Additional further work should focus on the applicability of our findings more widely to other saprophagous groups and particularly responses to global change.

There is a relative paucity of data on woodlouse ecology and most information comes from short-term studies considering only a few species (David \& Hanada, 2010). Our study demonstrates the importance of volunteer-led national recording schemes, such as the Non-marine Isopod Recording Scheme, in providing large-scale and long-term data. Indeed, without such national recording activity it would be impossible to deliver evidence on the effects of environmental change on macro-ecological processes. The value added to distribution data through the simultaneous assessment of habitat is immeasurable particularly in enhancing understanding of the ecology of neglected groups, such as woodlice.

ACKNOWLEDGEMENTS. The authors would like to thank the British Myriapod \& Isopod Group contributors to the Isopod Recording Scheme for providing distribution data. HR received support under the Biological Records Centre partnership between NERC (through the Centre for Ecology \& Hydrology) and the Joint Nature Conservation Committee.

\section{REFERENCES}

Beck J. \& Kitching I.J. 2007: Correlates of range size and dispersal ability: a comparative analysis of sphingid moths from the Indo-Austalian tropics. Global Ecol. Biogeogr. 16: 341-349.

Bolger D.T., Suarez A.V., Crooks K.R., Morrison S.A. \& CASE T.J. 2000: Arthropods in urban habitat fragments in southern California: area, age, and edge effects. Ecol. Appl. 10: $1230-1248$.

Bonte D., Baert L., Lens L. \& Maelfait J.P. 2004: Effects of aerial dispersal, habitat specialisation, and landscape structure on spider distribution across fragmented grey dunes. Ecography 27: 343-349.

Brandle M., Ohlschlager S. \& Brandl R. 2002: Range size in butterflies: correlation across scales. Evol. Ecol. Res. 4: 993-1004.

Comont R.F., Roy H.E., Lewis O.T., Harrington R., Shortall C. \& Purse B.V. 2012: Using biological traits to explain lady- 
bird distribution patterns. J. Biogeogr. 39: doi: 10.1111/j.1365-2699.2012.02734.x

Condit R., Ashton P.S., Baker P., Bunyavejchewin S., Gunatilleke S., Gunatilleke N., Hubbell S.P., Foster R.B., Itoh A., LaFrankie J.V., Seng Lee H., Losos E., Monkaran N., SuKumar R. \& Yamakura T. 2000: Spatial patterns in the distribution of tropical tree species. Science 288: 1414-1418.

Cowley M.J.R., Thomas C.D., Roy D.B., Wilson R.J., LeonCortes J.L., Gutierrez D., Bulman C.R., Quinn R.M., Moss D. \& GASTON K.J. 2001: Density-distribution relationships in British butterflies. I. The effect of mobility and spatial scale. J. Anim. Ecol. 70: 410-425.

Dallinger R., Berger B. \& Birkel S. 1992: Terrestrial isopods: useful bioindicators of urban metal pollution. Oecologia 89: $32-41$.

Dauber J., Purtauf T., Allspach A., Frisch J., Voigtlander K. \& Wolters V. 2005: Local vs. landscape controls on diversity: a test using surface-dwelling soil macroinvertebrates of differing mobility. Global Ecol. Biogeogr. 14: 213-221.

David J.F. \& Gillon D. 2009: Combined effects of elevated temperatures and reduced leaf litter quality on the life-history parameters of a saprophagous macroarthropod. Global Change Biol. 15: 156-165.

DAVID J.F. \& HANDA I.T. 2010: The ecology of saprophagous macroarthropods (millipedes, woodlice) in the context of global change. Biol. Rev. 85: 881-895.

Davies C.E., Moss D. \& Hill M.O. 2004: EUNIS Habitat Classification, Revised 2004. Report to European Environment Agency. European Topic Centre on Nature Protection and Biodiversity.

DAvis R.C. \& SutTon S.L. 1978: A comparative study of changes in biomass of isopods inhabiting dune grassland. Sci. Proc. R. Dublin Soc. (A) 6: 223-233.

DECAËNS T. 2010: Macroecological patterns in soil communities. Global Ecol. Biogeogr. 19: 287-302.

Donoso D.A., Johnston M.K. \& Kaspari M. 2010: Trees as templates for tropical litter arthropod diversity. Oecologia 164: 201-211.

EwERS R.M. \& DiDHAM R.K. 2006: Confounding factors in the detection of species responses to habitat fragmentation. Biol. Rev. 81: 117-142.

FATTORINI S. 2011: Insect rarity, extinction and conservation in urban Rome (Italy): a 120-year-long study of tenebrionid beetles. Insect Conserv. Divers. 4: 307-315.

Fitzpatrick U., Murray T.E., Paxton R.J., Breen J., Cotton D., SANTORUM V. \& Brown M.J.F. 2007: Rarity and decline in bumblebees - a test of causes and correlates in the Irish fauna. Biol. Conserv. 136: 185-194.

Fuller R.M., Cox R., Clarke R.T., Rothery P., Hill R.A., Smith G.M., Thomson A.G., Brown N.J., Howard D.C. \& Sтотт A.P. 2005: The UK land cover map 2000: Planning, construction and calibration of a remotely sensed, useroriented map of broad habitats. Int. J. Appl. Earth Observ. Geoinform. 7: 202-216.

Freckleton R.P., Harvey P.H. \& Pagel M. 2002: Phylogenetic analysis and comparative data: a test and review of evidence. Am. Nat. 160: 712-725.

Gaston K.J. \& Fuller R.A. 2009: The sizes of species' geographic ranges. J. Appl. Ecol. 46: 1-9.

Gaston K.J., Blackburn T.M. \& Lawton J.H. 1997: Interspecific abundance-range size relationships: an appraisal of mechanisms. J. Anim. Ecol. 66: 579-601.

Gaston K.J., Blackburn T.M. \& Spicer J.I. 1998: Rapoport's rule: time for an epitaph? Trends Ecol. Evol. 13: 70-74.
Gongalsky K.B., Savin F.A., Pokarzhevskit A.D. \& Filimonova Z.V. 2005: Spatial distribution of isopods in an oak-beech forest. Eur. J. Soil Biol. 41: 117-122.

GREGORY S. 2009: Woodlice and Waterlice (Isopoda: Oniscidea \& Asellota) in Britain and Ireland. Centre for Ecology \& Hydrology, Wallingford, $176 \mathrm{pp}$.

GREGORY R.D. \& GASTON K.J. 2000: Explanations of commonness and rarity in British breeding birds: separating resource use and resource availability. Oikos 88: 515-526.

Gutierrez D. \& Menendez R. 1997: Patterns in the distribution, abundance and body size of carabid beetles (Coleoptera: Caraboidea) in relation to dispersal ability. J. Biogeogr. 24: 903-914.

Hanski I., Kouki J. \& HalkKa A. 1993: Three explanations of the positive relationship between distribution and abundance of species. In Ricklefs R.E. \& Schluter D. (eds): Species Diversity in Ecological Communities. The University of Chicago Press, Chicago, pp. 108-116.

Harding P.T. \& Sutton S.L. 1985: Woodlice in Britain and Ireland: Distribution and Habitat. Institute of Terrestrial Ecology, Huntingdon, $151 \mathrm{pp}$.

Hartley S., Kunin W.E., Lennon J.J. \& Pocock M.J.O. 2004: Coherence and discontinuity in the scaling of species distribution patterns. Proc. R. Soc. Biol. Sci. (B) 271: 81-88.

Hassall M., Tuck J.M., Smith D.W., Gilroy J.J., Addison R.K. 2002: Effects of spatial heterogeneity on feeding behaviour of Porcellio scaber (Isopoda: Oniscidea). Eur. J. Soil Biol. 38: $53-57$.

Hättenschwiler S., Tiunov A.V. \& Scheu S. 2005: Biodiversity and litter decomposition in terrestrial ecosystems. Annu. Rev. Ecol. Evol. Syst. 36: 191-218.

Holt R.D. 2003: On the evolutionary ecology of species ranges. Evol. Ecol. Res. 5: 159-178.

Jones K.E., Purvis A. \& Gittleman J.L. 2003: Biological correlates of extinction risk in bats. Am. Nat. 161: 601-614.

JudD S. \& HoRwITz P. 2003: Diversity and biogeography of terrestrial isopods (Isopoda, Oniscidea) from southwestern Australia: organic matter and microhabitat utilization in seasonally dry landscapes. Crustac. Monogr. 2: 191-215.

Kotze D.J., Niemelä J., O’Hara R.B. \& Turin H. 2003: Testing abundance-range size relationships in European carabid beetles (Coleoptera, Carabidae). Ecography 26: 553-566.

Lavelle P., Bignell D., Lepage M., Wolters V., Roger P., Ineson P., Heal O.W. \& Dhillion S. 1997: Soil function in a changing world: the role of invertebrate ecosystem engineers. Eur. J. Soil Biol. 33: 159-193.

Maraun M., Martens H., Migge S., Theenhaus A. \& Scheu S. 2003: Adding the "the enigma of soil animal diversity": fungal feeders and saprophagous soil invertebrates prefer similar food substrates. Eur. J. Soil Biol. 39: 85-95.

McCullagh P. \& Nelder J.A. 1989: Generalized Linear Models. Chapman and Hall, London, 511 pp.

MCNALLY R. 2002: Multiple regression and inference in ecology and conservation biology: further comments on identifying important predictor variables. Biodiv. Conserv. 11: 1397-1401.

Oliver T.H., Hill J.K., Thomas C.D., Brereton T. \& Roy D.B. 2009: Changes in habitat specificity of species at their climatic range boundaries. Ecol. Lett. 12: 1091-1102.

Pagel M. 1999: The maximum likelihood approach to reconstructing ancestral character states of discrete characters on phylogenies. System. Biol. 48: 612-622.

Paoletti M.G. \& Hassall M. 1999: Woodlice (Isopoda: Oniscidea): their potential for assessing sustainability and use as bioindicators. Agric. Ecosyst. Environ. 74: 157-165. 
Paoletti M.G., Osler G.H.R., Kinnear A., Black D.J., Thomson L.J., Tsitsilas A., Sharley D., Judd S., Neville P. \& D'InCA A. 2007: Detritivores as indicators of landscape stress and soil degradation. Austr. J. Exp. Agric. 47: 412-423.

Paradis E.J., Claude J. \& Strimmer K. 2004: APE: analyses of phylogenetics and evolution in R language. Bioinformatics 20: $289-290$.

Peitgen H.-O., Jürgens H. \& Saupe D. 1992: Fractals for the Classroom. Part One: Introduction to Fractals and Chaos. Springer, New York, $450 \mathrm{pp}$.

Pocock M.J.O., Hartley S., Telfer M.G., Preston C.D. \& KUNIN W.E. 2006: Ecological correlates of range structure in rare and scarce British plants. J. Ecol. 94: 581-596.

Quinn G.P. \& Keough M.J. 2002: Experimental Design and Data Analysis for Biologists. Cambridge University Press, Cambridge, $x$ vii $+537 \mathrm{pp}$

Rundle S.D., Bilton D.T., Aвbott J.C. \& Foggo A. 2007: Range size in North American Enallagma damselflies correlates with wing size. Freshw. Biol. 52: 471-477.

Rushton S.P. \& Hassall M. 1987: Effects of food quality on Isopod population dynamics. Funct. Ecol. 1: 359-367.

Souty-Grosset C., Badenhausser I., Reynolds J.D. \& Morel A. 2005: Investigations on the potential of woodlice as bioindicators of grassland habitat quality. Eur. J. Soil Biol. 41: $109-116$.

Smart S., Maskell L.C., Dunbar M.J., Emmett B.A., Marks S., Norton L.R., Rose P., Henrys P. \& Simpson I.C. 2010: An Integrated Assessment of Countryside Survey Data to Investigate Ecosystem Services in Great Britain. NERC/Centre for Ecology \& Hydrology, Lancaster, UK, 230 pp.

Sutton S.L., Hassall M., Willows R., Davis R.C., Grundy A. \& SUNDERLAND K.D. 1984: Life histories of terrestrial isopods: a study of intra- and interspecific variation. Symp. Zool. Soc. Lond. 53: 269-294.

TAJOvsKY K. 2001: Colonization of colliery spoil heaps by millipedes (Diplopoda) and terrestrial isopods (Oniscidea) in the Sokolov region, Czech Republic. Restor. Ecol. 9: 365-369.

Topp W., Kappes H., Kulfan J. \& Zach P. 2005: Distribution pattern of woodlice (Isopoda) and millipedes (Diplopoda) in four primeval forests of the Western Carpathians (Central Slovakia) Soil Biol. Biochem. 38: 43-50.

TSAI M., DAI C. \& CHEN H. 1998: Desiccation resistance of two semiterrestrial isopods, Ligia exotica and Ligia taiwanensis (Crustacea) in Taiwan. Comp. Biochem. Physiol. (A) 119: 361-367.

Vilisics F., Elek Z., Lovei G.L. \& Hornung E. 2007: Composition of terrestrial isopod assemblages along an urbanisation gradient in Denmark. Pedobiologia 51: 45-53.

WANG M. \& Schreiber A. 1999: Population differentiation of the woodlouse Oniscus asellus in Central Europe (Isopoda: Oniscoidea). J. Crustac. Biol. 19: 301-312.

Warburg M.R., Linsenmair K.E. \& Bercovitz K. 1984: The effect of climate on the distribution and abundance of Isopods. Sympos. Zool. Soc. Lond. 53: 339-367.

WARDLE D.A. 2002: Communities and Ecosystems: Linking the Aboveground and Belowground Components. Princeton University Press, Princeton, $400 \mathrm{pp}$.

Weisberg S. 1980: Applied Linear Regression. Wiley, New York, $310 \mathrm{pp}$.

Williamson M. \& Gaston K.J. 1999: A simple transformation for sets of range sizes. Ecography 22: 674-680.

Wilson R.J., Thomas C.D., Fox R., Roy D.B. \& Kunin W.E. 2004: Spatial patterns in species distributions reveal biodiversity change. Nature 432: 393-396.

Received December 6, 2011; revised and accepted July 2, 2012 